\title{
A place for mobility in metaphors of youth transitions
}

\section{Valentina Cuzzocrea}

To cite this article: Valentina Cuzzocrea (2020) A place for mobility in metaphors of youth transitions, Journal of Youth Studies, 23:1, 61-75, DOI: 10.1080/13676261.2019.1703918

To link to this article: https://doi.org/10.1080/13676261.2019.1703918

曲 Published online: 20 Dec 2019.

Submit your article to this journal 준

Џlll Article views: 196

Q View related articles $\llbracket$

View Crossmark data \lceil 


\title{
A place for mobility in metaphors of youth transitions
}

\author{
Valentina Cuzzocrea \\ Dipartimento di Scienze Politiche e Sociali, Università degli Studi di Cagliari, Cagliari, Italy
}

\begin{abstract}
Metaphors are central in the study of youth; in fact, it has been argued that 'youth' itself could be considered a metaphor. In a recent assessment of transition-related metaphors, Cuervo and Wyn [2014. "Reflections on the Use of Spatial and Relational Metaphors in Youth Studies." Journal of Youth Studies 17 (7): $901-$ 915.] have noted that such metaphors as 'niches', 'pathways', 'trajectories' and 'navigations', often contain an element of movement. However, it is still under-debated how we can systemically incorporate mobility into the study of young people to capture the precarity characterising their lives (a), but also heuristically link to metaphors used to describe the changing shape of careers of young people (b). Indeed, scholarship on 'boundaryless careers' and 'peripatetic careers' appear to have developed separately from the youth-related literature, albeit dealing in part with similar issues. Departing from Furlong's work on metaphors in youth studies, this article interrogates potential for intertwining research lines within the growing debate on mobility in youth transitions. The article develops at a conceptual level; however it takes on Furlong's legacy in the sense of contributing to a youth research agenda which is attentive to both the creation of new imaginative categories for the study of current conditions of youth, and the challenges that emerge in discursively positioning youth in society.
\end{abstract}

ARTICLE HISTORY

Received 6 August 2019

Accepted 5 December 2019

\section{KEYWORDS}

Youth transitions; metaphors; careers; precarity; mobility; pinball

\section{Introduction: Furlong's work and the production of metaphors}

In youth studies, Furlong has been one of the main commentators on the decline in the number of young people in employment (e.g. Furlong 2015 ), as well as on the underlying cultural mechanisms leaving even those that actually are in employment in conditions of marginality (Furlong 2005). A specific focus within Andy Furlong's work has been on the recent realities of those occupying the 'NEET' status as a proxy for describing the condition of worklessness (Furlong 2006), and with it, the subjective experience of the casualisation of work. His work has also stressed the potential that this overall condition has created a dualization of citizenship and overall precariousness (Standing 2011). A variety of delicate mechanisms within western countries have emerged, encompassing the changing shapes of educational systems to support the insertion of young people into the labour market. He conveyed this through 'the Brazilianization of youth transitions' (Furlong and Kelly 
2005), echoing Beck's term famously used in The Brave New World of Work (2000) to talk about global processes of precarization. The way in which Furlong's attention oscillates between data and experiences distinguishes his work and allows him to synthetise a youth Zeitgeist without the risk of dogmatism. Furlong had a rare ability to navigate facts and figures, whilst simultaneously portraying the worldviews of young people and their apparent - and at times less apparent - struggles. His work also sheds light on class conditions and the way in which these conditions, in turn, shape the ambitions, orientations and aspirations of young people.

The reference to Beck in the aforementioned article is made 'at a metaphorical level', with the intention of opening up 'new lines of thinking' (Furlong and Kelly 2005, 209). It is from such a statement that I proceed in my discussion of the use and value of metaphors in studies of young people, further reflecting on comments already made on the production of metaphors in this area of study (Evans and Furlong 1997; Furlong 2009; Wyn, Lantz, and Harris 2011; Cuervo and Wyn 2014). In a landmark book first published in 1997 (and then republished in 2007), Andy Furlong (with Fred Cartmel) proposed that we view youth transitions by using the metaphor of a mode of transport. It was argued that in the past young people constructed their paths as if they were travelling by means of public transportation, such as trains, suggesting that the direction taken was predictable and somehow linear. This stands in contrast to the proliferation of directions possible within contemporary western societies. In such conditions, class, gender and ethnicity function in increasingly hidden ways, resulting in young people loosing clear points of reference and having the impression that they determine their own paths, through their own means - a mechanism termed as 'epistemological fallacy'. In seeking a suitable metaphor for current modes of transportation towards adulthood, Furlong and Cartmel suggested that it is as if young people, under these new circumstances, find themselves travelling towards adulthood as if they were in private cars, taking the most disperse directions and finding their own ways within a plethora of opportunities. Such a perspective has caused what they termed an 'over-emphasis on the significance of individual reflexivity' in the field of youth studies. ${ }^{1}$

This metaphor has become an unquestionable point of reference for those studying youth transitions. It illustrates, among other things, the impact of individualisation theories and the risk society on youth studies and the dominant Zeitgeist for young people facing the difficult transition to adulthood, encompassing fears, dilemmas, anxieties, and hidden costs. Following this vein, I start by reflecting on the value of metaphors in understanding social phenomena more generally, and in particular, social phenomena that mark the transitions towards adulthood. This review considers how the metaphors produced in this field are often characterised by spatial and /or mobility aspects (Cuervo and Wyn 2014). Such an analysis offers the possibility of expanding on an emerging area within youth transitions studies, which is the study of how (geographical) mobility accompanies and/or at times enhances or permits this transition in the life course. After considering a range of metaphors produced within youth studies, I scrutinise those that broadly relate to transitions from education to the labour market, another area of work dear to Andy Furlong.

In facing recent developments within this body of work, I expand upon Furlong's original thought: for instance, I am not aware of any work having been done by him on youth mobility. Spatial and environmental characteristics of places where young people are located are predominantly treated in his work as structural characteristics. This is 
evident, for instance, in his work with Forsyth on youth in Scotland. In this, one can find 'geographical barriers' (i.e. living in remote areas, leaving home, accommodation, travelling) in the section, 'Experience of barriers to participation in higher education' (Forsyth and Furlong 2000,37-39). Or, in the example of 'accommodation and travel' as an item of 'economic disadvantage' (Forsyth and Furlong 2003, 33-37). The main argument is here that in conditions of hardship, families may make a difference in young people's decisions by providing free accommodation to students willing to commute to attend university - a topic very much entrenched in UK based youth literature.

Yet, I reconnect to the intentions with which Furlong conducted work on youth - and which inspired many - which I see as contributing to a youth research agenda that is attentive to the creation of new imaginative categories for the study of current conditions of youth, and the challenges that emerge in discursively positioning youth in society. I thereby argue for a systemic consideration of mobility within metaphors produced in these cognate disciplines and possibly for a stronger connection between them. I then propose the metaphor of the 'pinball' as a possibility to convey these suggestions.

\section{Metaphors in youth studies}

It is important to reflect on the general role of metaphors. In 'Why Metaphors are Necessary and Not Just nice', Orthony (1975) argued for a more than ornamental role for metaphors. For Cuervo and Wyn, 'metaphors are essential precisely because they make particular elements of our social world visible by taking an idea from one realm and putting it into a different context' $(2014,3)$. Ervas and Gola stress that the flexibility of metaphors allow for consistency across time in referring to experiences $(2016,59)$. In a famous article in the Journal of Vocational Behaviour, Inkson states that 'a metaphor provides a powerful tool for us to express ourselves, and at the same time betrays deeper constructs in our thinking' (Inkson 2004, 97). For Evans and Furlong, metaphors:

[have] ... evolved in ways which reflect the dominant theoretical perspectives of the time. Each metaphor presents ways of analysing and understanding the young person's interactions with his or her social milieu and typical sequences of events between adolescence and adulthood. (Evans and Furlong 1997, 17)

In a book which advocates reflection on metaphors in social theory, Rigney considers both its 'uses and abuses', warning that, 'metaphorical thinking has its powers, but also its hidden snares and pitfalls' (2001, viii). For instance, he proposes reflection on whose interest the metaphor serves $(2001,204)$. If we have a predilection for a particular metaphor, says Inkson, this 'may constrain our ability to see careers in terms of alternative, equally plausible, metaphors' (Inkson 2004, 98). This section seeks to discuss the role of metaphors in understanding the experiences of young people specifically.

In a recent article on young people in Italy, Leccardi has suggested that in view of profound social changes, young people can be considered 'instead of a specific stage of life, [...] a metaphor dealing with social change in a time of uncertainty' (Leccardi, Cuzzocrea, and Bello 2018, 22). This proposal is not exaggerated if we consider that within the landmark collection of youth cultures, Resistance Through Rituals, a very similar point is made (Clarke et al. 2006 [1976], 10, 56; Willis 2006 [1976], 96). Tejerina has developed six metaphors/images to explain precariousness of young Spaniards: 'living from hand to mouth', 
'being on the tightrope', 'stressed like crazy', on 'standby', 'taking a step backwords' and 'I want to be normal'; all of which convey a sense of anxiety and feeling overwhelmed (2019, 94-96). Another famous metaphor, though it does not pertain directly to the idea of transition, is that of peer companionship as a 'tribe'. This is an expression that was coined by the French sociologist Maffesoli (1996), then brought into youth subcultural sociology by Bennett (1999). This metaphor has served as a focus on the theme of 'postmodern' fluidity in youth research, which has continued to thrive in the study of more recent youth aggregations, for instance those characterised by the use of social media (as in the recent collection edited by Hardy, Bennett, and Robards 2018).

The objective that I aim to achieve by reconsidering the role of metaphors in youth studies is not to compose an exhaustive review - once one starts paying attention to the production of metaphors in this field of study, it is difficult to stop - but to further reflect on the underpinnings of a position such as that of Cuervo and Wyn, according to whom 'the sociology of youth and the broader field of youth studies are replete with metaphors, especially spatial metaphors' (2014, 915, my italics). In view of the ever-increasing role of the issue of mobility in youth studies, I investigate further the possible role of the 'spatial' within this field. When it comes to conceptualising education-towork transitions, developing metaphors can help to explain the process of moving from education and training and into the labour market in a particular place or at a specific point in time (Evans and Furlong 1997). ${ }^{2}$ With regard to the evolution of conceptual ideas, in the 1960s and 1970s, youth transitions tended to be conceptualised as niches or pathways into work, but from the 1980s onwards a more nuanced approach has been adopted by youth sociologists through the use the expressions such as 'navigations' and 'trajectories' (as summarised by Evans and Furlong 1997; Furlong 2009; Cuervo and Wyn 2014). A recognition of the complexity of transitions is reflected in the idea of structured individualism and acknowledgement of socio-demographic diversity in the durations of education to work trajectories, with emphasis on the life chance defining power of locality according to geographical location (MacDonald et al. 2005; Sharma 2013; Sørensen and Pless 2017; Waters 2018; Cuzzocrea 2019). However, less prominent in the discussion have been the ramifications for transitions in work trajectories that may be inherently peripatetic.

In recent years, a presupposed linearity of 'old' transitions as 'gold' transitions (Kohli 1986) has been questioned (Goodwin and O'Connor 2005) and with that, the 'lost world' of secure employment that they referred to (Fevre 2007). Similarly, up-to-date accounts have further challenged the idea of 'private transportation' as being a good metaphor for contemporary youth transitions; Magaraggia and Benasso (2019) for instance, propose a substitution with sharing-modes of transportation to emphasise a collective dimension in the transition. General transformations are in part due to the structural conditions having turned into increasingly difficult realms for young people. As a consequence, coming back to the metaphor of transportation, private cars have essentially become out of the reach of young people. Clearly, however, it is not only economic restrictions that have changed in this scenario, but also a broader new cultural sensibility on how to navigate the transition itself and the processes of sense making around it: 'transition, which is itself a metaphor, takes on new meaning if the paid labour market - as a space of arrival- is increasingly a space marked by uncertainty, precarity and 
ambivalence' (Furlong and Kelly 2005, 223). Walther Heinz makes a similar reflection, when arguing that:

... as a metaphor for the life course, trajectory applies to continuous careers, which are characteristics of orderly pathways in the internal labour markets of large companies and state bureaucracies of industrial societies. It does not reflect less ordered pathways, especially those of women, and of job entry and job exit cohort in the 1990s, who were confronted with much less employment stability than earlier cohorts[...] therefore, "transitions and sequences" seem to be better suited for describing the "contingent life course". $(2003,199)$

We know that the aspects which symbolise the attainment of independence are usually stressed, if not overstressed in youth research (Furlong 2009; Wyn, Lantz, and Harris 2011; Cuzzocrea 2018). The proliferation of metaphors on transitions has a lot to do with the centrality of the idea of the markers as a way to conceive of the end of youth, with a lot of implications on normative expectations (Wyn, Lantz, and Harris 2011), and in particular those shaped by intergenerational relations. This approach has strong links with youth policy research (Cuervo and Wyn 2014), a domain in which the 'master metaphor' in youth studies (i.e. 'transition') has been critically discussed (Cuervo and Wyn 2014, 4). Akin to this master metaphor is the metaphor of 'yo- yo' transitions, by which Biggart and Walther (2006) famously indicated the current fragmentation of a transition which is not linear anymore. A similar suggestion is also present in the 'shuffle' metaphor (Benasso 2013).

It is noteworthy that together with Karen Evans, Furlong underlined the importance of metaphors in a way which reflects on the overall state of the field of youth studies:

... metaphors for processes of transitions to adult roles, particularly into work, have evolved in ways which reflect the dominant theoretical perspectives of the time. Each metaphor presents ways of analysing and understanding the young's person interactions with his or her social milieu and typical sequences of events between adolescence and adulthood. (Evans and Furlong 1997, 17)

Such discussion brings us to the conclusion that these shifts reflect the emphasis put to either structure and/or agency to various extents at different points in time within the development of youth studies (Evans and Furlong 1997; Furlong 2009).

\section{Metaphors in 'new careers' studies}

Having explored the use and proliferation of metaphors in youth studies, I now turn to explore some of the so-called 'new career literature' (Arthur, Inkson, and Pringle 1999; Mignot 2004). This field has also offered several metaphors for describing erratic professional paths, perhaps having struggled to define them through conventional or less imaginative terms. As is widely recognised, casualisation of work and precarization of careers have hit young people the hardest. We could therefore say that the object of reflection is not so different between the two subdisciplines, the main contrast being that in 'new career studies' this fragmentation has mostly been referred to in relation to organisational boundaries and the effect that the dismantling of organisational careers has on agents, rather than on transitions to adulthood. I therefore explore this production and then question the role of mobility within it. 
The old understanding of career is that of a linear trajectory of interconnected jobs within a single organisation with upward vertical mobility. The term career derives from the Latin carraria (a road or carriageway), and then, from the sixteenth century, a racecourse and a gallop (Williams 1976). Later, in the aftermath of deindustrialisation and extensive restructuring of firms and organisations, the term career has changed in meaning. In this article, I review those metaphors that have been used to refer to a destandardization of the labour market, such as protean careers, portfolio careers, boundaryless careers and peripatetic careers. The expression 'protean careers' was inspired by the Greek god Proteus who 'could change shape at will'. It is encompassed of a person's 'varied experiences in education, training, work in several organisations, changes in occupational fields' (Hall 1976, 201). The emphasis is on the individual's adaptability. Similarly, there is a tendency to use the expression 'portfolio careers' when the emphasis is on performing a variety of skills and in the variability of tasks (Cohen and Mallon 1999). One's skills are deemed to define their employability, which is supposed to be dynamic and adaptable.

The idea of a 'boundaryless career' was launched by Arthur (1994). It refers to careers which develop across a range of organisations over time. This results from a profound restructuring of employment, indicating the fading away of boundaries (Arthur and Rousseau 1996a, 1996b). There have been attempts to assess what kind of boundaries this conceptualisation refers to (Rodrigues, Guest, and Budjanovcanin 2016, 682), and whether the empirical data actually sustains such a metaphor (Rodrigues and Guest 2010, 1162), which has been used widely to 'highlight trends in contemporary careers' (Rodrigues, Guest, and Budjanovcanin 2016, 670). The metaphor of the career as a journey has also been suggested. Journeys have beginnings and ends, 'with purposes connecting them- a reassuring image' (Nicholson and West 1989, 181). More recently this has come to mean 'rat race'- a pejorative meaning that explicitly carries with it an element of mobility. Generally, Inkson explores nine career metaphors $(2004,2007)$ : career as inheritance, construction, cycle, matching, journey, encounters and relationships, roles, resources, and story, establishing various ways to link the skill of an individual to conscious planning. ${ }^{3}$ The metaphor of career as a journey sees it explicitly in terms of mobility and, by raising attention on 'disorder', it somehow entails mobility, while excluding immobility. Inkson's definition is that this movement can take place 'geographically ${ }^{4}$, between jobs, between occupations, or between organizations' (2004, 103). The idea of a journey, however, does not specify the speed, nor the direction(s) taken $(2004,101)$. It is interesting to note that the intensifcation of movement implied in these moves (especially in the pejorative notion of 'ratrace') contains an element of time acceleration which may easily veer out of control.

There is at least another term tied to mobility and careers: 'peripatetic career'. The expression carries with it a physical connotation in that the peripatoi were the colonnades of Lyceum in Athens where Aristoteles and others would meet whilst walking to have their discussions. Its use in scholarly literature seems non-technical; for instance, it is used for the study of diplomatic careers to indicate that within a couple, one is usually brought to places following the spouse's career, without a clear direction of their own over the years. This movement, which has strong gender connotations, is often a focus in the socalled 'dual earners' literature. In an article located within this literature, Ackers (2004) uses this expression to challenge existing migration theory, individualistic human capital and new Marxist approaches and to question the role of suvranational actors in spreading the 'mobility promise' (Cairns 2014). The term 'peripatetic' brings with it the 
connotation that is understandable in the domain of dual career couple, but not in general, i.e. that there is one leading person in the movement, the sole partner having a career or the one more engaged with it, as if there was a breadwinner even in dual earners couples. Yet, it remains unclear what happens when the one who moves in search of a career does not have family commitments. Ultimately, it also begs the question as to whether it is always the case that within a dual career couple one career is constantly predominant over the other, especially in the case of women in high careers.

My argument within this debate is that whilst most of the existing career literature contain an element of movement across boundaries, it engages with the underpinning of geographical movement unsatisfactorily. Only sporadic attention is given to it (for example, Rodrigues, Guest, and Budjanovcanin 2016, 681). Even the influential book 'The Corrosion of Character' (Sennett 1998), which has fuelled much of the debate on precarity during the 2000 s, begins by telling the story of a man (Rico, whom the author met on a plane), whose career and life had been characterised by continuous movements across the US in search of career and employment opportunities. Rico's career is narrated as in contrast with that of his father, Enrico, which was marked instead by stability, intended also in a geographical sense. However, this aspect has remained at the periphery of the wider debate of possible hardship entailed in these mechanisms.

I argue that the lack of engagement with (geographical) mobility in this work remains unjustified. Whilst there is a sense in which this may exacerbate precariousness, it has not been systemically explored or incorporated. This absence is even less justified vis $a$ vis the emphasis on reflexivity in making careers, which is underpinned fully within the 'new career' literature. The overemphasis that this puts on agency and the 'project of the self' is in stark contrast with the assumption that careers should just happen 'at home', a criticism that on converse has made its way in social science in general following a criticism of the 'amobile assumptions' (Holdsworth 2013,3). In the cognate field of youth studies, in fact, this concern has been conceptualised at the micro level through the lens of 'spatial reflexivity' (Cairns 2014). Young people may be encouraged to consider relocating so as to get better qualifications and ultimately construct a career or to seek better employment opportunities and so on, following the so called 'mobility promise' (Cairns 2014). At the same time, they are encouraged to take mobility into account when making life decisions. This does not mean that everyone is going to be mobile, but that mobility is increasingly likely to be considered. Even the 'peripatetic' idea of career contains many limitations. Despite an abundance of existing metaphors in this field, I therefore propose that much space could in fact be used to create metaphors which can better encapsulate the current meanings of mobile transitions of youth.

\section{Spatiality and mobility as key to understanding youth: towards an integrated approach}

I develop in this section a perspective on the wider usefulness of looking at mobility with reference to the debate so far summarised. Youth studies and career studies are not by any means the only ones replete with metaphors. Cultural analysis is too, and the metaphorical significance of mobility is explained by the fact that 'cultures travel as well as people' (Rojeck and Urry 1997, 10-11). Jokinen and Veijola (1997) argue that it is now almost impossible to escape from travel as a metaphor. Borrowing the approach of Raymond 
Williams in 'Keywords' (1976), Salazar recently compiled a collection which focuses on six key figures of mobility, where 'figures not only connote a representation of an (ideal-type) person but also a lived experience of a particular $\operatorname{kind}^{\prime}(2017,8)$. Each of these 'conceptmetaphors' are based on the thought of a classical author. They are: the nomad, the exile, the pilgrim, the tourist, the pedestrian and the flaneur. Whilst there has been some recognition of the importance of mobility in past research (Cresswell 2010, 28; Salazar 2010), scholarship within the mobility turn ${ }^{5}$ has focused on critically examining the discursive representation of space. For instance, 'youth circulation [...] is now a more commonplace occurrence' (Cairns 2015, 2), and the modalities and implications by which the acts of moving unfold in the cultural structure of contemporary society become especially interesting. Increasingly important is the 'role of place in shaping young people's social networks, identities and aspirations regarding employment' (White and Green 2015, 295).

To remain on structural grounds and following Furlong's vein, I start from a basic definition of mobility as it may pertain to young people. In contrast to migration, mobility is about moves made by 'free choice', and is motivated by personal realisation and willingness to explore the world, for instance, typical of students (Ambrosini 2017). In a recent introduction to migration studies, Ambrosini argues that Brexit has acted as a sudden and traumatic event, having broken the assumption which he defines as 'for us comforting', of being somehow on the privileged side. He cuts a long story short by defining Brexit as being motivated by the intention of stopping the freedom of movement of those coming from peripheral areas of the EU, i.e. those more interested in the search for better opportunities, and with that the UK has restated that 'we are still potential migrants' $(2017,15){ }^{6}$ I find this wording inspiring as I think it reveals dimensions of social structure segregations, a distinction that is rich with implications for the transition to adulthood because it complicates the assumption of 'free will' behind the enactment of mobility, an assumption often emphasised, for instance, in youth policies.

Mobility appears to carry assumptions of acquired privilege, but maintains slippery ambivalence and precarious status and is indicative of social stratification. There may not be a clear distinction between mobile and immobile young people (Thomson and Taylor 2005), but important social differences exist between those whose mobility may be enhanced or easily reduced and those who, whether or not they are willing to move, cannot escape their present conditions. The distinction between 'mobility capacity' and 'mobility imperative' has been proposed as heuristic in youth studies (Cairns 2015, 9).

Others prefer to talk about 'mobility imperative' (Farrugia 2016), whilst 'mobility capital' (Murphy-Lejeune 2002; Holdsworth 2006) is an expression used to indicate readiness to relocate to take an educational or work opportunity should it arise elsewhere.

Mobility-sensitive approaches have been moving fast, following some specific invitations to address spatiality and mobility more directly than before, in both youth studies and education studies (Farrugia and Wood 2017; Robertson, Harris, and Baldassar 2017; Finn and Holton 2019). Extending Furlong's legacy, mobility can be seen as a way to get a glimpse on the ground. Youth studies in particular reflect on mobility to explore transitions to adulthood, considering it as a possible 'marker' (Cairns 2014; Cuzzocrea and Mandich 2016; Krzaklewska 2019). Holdsworth stresses how important leaving home to go to university is as a rite of passage for young people $(2006,496)$, suggesting that the social division between those who moved from their parent's house to attend university 
and those who could not afford it may take wider meanings than just an economic division. Migration scholar Izabela Grabowska examines the interplay between agency and structure (2016) when holding one's first job abroad. She also reiterates the distinction made by Sackmann and Wingens (2003) between the first job abroad as a rupture, interruption, change, bridge, return and fusion. 'Spatial dilemmas' (Cairns 2014) - namely, concerns relating to where the transition to adulthood occurs - highlight ambivalences in the capacity of young people to take action, as well as social injustices, marginalisation and exclusion.

In reference to this discussion, I wish to make the point that metaphors on youth and careers would work better if they were not only more interconnected, but also if they systemically included an element of mobility. For instance, the metaphor of the boundaryless career -born, as I have shown, in the domain of 'new career' or (in wider terms) organisational studies - is free from generational connotations. However, if we consider the increased articulation from linear careers, we are able to figure out what added effort is implied in the new configuration, as well as the intensification of work -and therefore the speed of action, which can be translated into more fatigue, and possibly, more instability. The simple decision of whether or not to move- to an organisation, a job, but also to another country, definitely implies additional work, and activation of one's network in order to ponder the decision, even if it is only short term move. The metaphor of the 'boundaryless career' could in fact be used to convey this meaning outside of its original one, related to organisational boundaries. In turn, mobility is mostly intended in terms of passages from one life moment to another in metaphors of youth studies, while the relevance of destructured work contexts is somehow left in the shadows. Indeed, the 'paths' that young people are called upon to draw encompass all these dimensions, while being increasingly more likely to be on the move (in a geographical sense). At present, 'pathway' is in this sense the medium that draws career studies and youth studies together. Yet, there is something unconvincing about how implicit movement remains in this metaphor, especially considering that it is, in fact, movement-based.

There has been criticism about whether the 'traditional' transition metaphor is still valid (Wyn, Lantz, and Harris 2011). However, more than a criticism of the functions of metaphors in youth studies, this is an invitation to go beyond a linear and developmental assumptions in relation to the experiences of young people. A metaphor does not 'crystallise' a phenomenon; the intention of any metaphor is to visualise a conceptual idea; in this case, a dynamic idea that is understudied and underconceptualized (Furlong 2009). I therefore invite reflection upon new metaphors that can enable a better understanding of youth and the current conditions in which they live, that can in turn capture the fluidity of their current struggles whilst still paying attention to structural conditions. To this end, I make my proposal for a new metaphor, whereby young people could be seen as 'pinball youth'.

\section{A new metaphor: pinball youth?}

In this section, I introduce the metaphor of "pinball youth" ${ }^{7}$ as an imaginative means of representing the uncertainty experienced by young people in transitional stages. The metaphor suggested here is not made on the basis of a particular dataset, but as a general reflection regarding several kinds of mobility experiences common amongst 
young people. In particular, this metaphor can be taken to represent effects of the casualisation of employment discussed above, and to convey at the same time the intensification of mobility which may encompass precarization and uncertainty. It is all the more fitting since the game inherently involves stopping and starting, just as in the employment sphere, as well as being representative of reaching goals and overcoming obstacles and boundaries.

As anyone who has ever played the game in its original format or in its contemporary digital incarnations knows, a pinball table is a device in which a small ball is propelled by a plunger, and points are scored when it rolls down a slanted surface, peppered with pins and targets. The player tries to stop the ball from rolling out of the game at the bottom of the table by manipulating two manually controlled flippers that are not quite large enough to ensure that the ball in play cannot slip through. First, the image conveys a degree of casualisation with regard to life planning, extending to ceding agency to an external party. The metaphor serves here to underline the possibility that, despite an enjoyment of the game, there may be a lack of agency that many young people experience in controlling a work path. Mechanisms might be in place, but as can be the case with a pinball machine, the direction the ball takes at any given moment is unpredictable, as are the effectiveness of movements made to keep it in play. We can also observe that a pinball game is of fixed duration, but with repeatable episodes of movement, with each push of the ball onto the table sending the individual back to the starting point rather than contributing to a cumulative trajectory.

The idea of a pinball game thus gives a means of understanding what spatial movement can do to the ability to direct a career trajectory. Those not playing might be made to feel that their spatially grounded career strategies are something of an anachronism when compared to these new cosmopolitan lifestyle choices (Tomaney 2014; Plöger and Kubiak 2018). The pinball game therefore becomes a way to 'actualise' work goals inherited by previous generations (as much as the pinball game may be old fashioned, there exists multiple online versions for today's youth). The additional burden implied in embodying a pinball youth lifestyle might go unrecognised, or seen as a minor but inevitable part of the process. Expressed in this way, the pinball metaphor strongly resonates with the idea of the 'epistemological fallacy' (Furlong and Cartmel 1997), much as scholarship points to the inherent pitfalls in a policy focus on employability and activation policies.

Another consideration regards the individualization of the experience of playing the pinball game and this is perhaps its darkest interpretation. Connection with others takes place primarily in terms of the amount of success one generates relative to others. Similarly, a career may become competitive within a cohort. It is possible that a cohort share similar goals, but the 'game' remains based on individual resources. Given that networks may be weak, constructing a mobile career requires additional burden and may be seen as an exceptional pursuit, perhaps even exceeding aspects of a 'ratrace' that has become familiar to career construction in neo-liberal contexts. Moreover, even if there is a 'path' to navigate, this is more likely, in mobile careers, to be characterised by 'yo-yo' and 'shuffle' movements. Constant effort is required just to 'stay in the game' of living in mobile situations. Ongoing effort is required to invest in ones skillset and the skills acquired may not even be aligned or useful in the end. Such unpredictable outcomes associated with exercising mobility, reveal a complexity that is inherently hazardous. 
Whilst potential gains can swiftly multiply, as in the game, it is also possible to loose everything with one false move.

At the same time, the pinball metaphor also makes space in transitions theory for appreciating that attempts to move from education and into the labour market can have a playful personal development dimension. And just as the pinball game has targets to meet and obstacles to avoid, so do young people. The 'pinball' metaphor therefore expresses a self-interested- as much as externally exploitative- strategy to becoming an adult, and one that we should recognise as such. This metaphor also enables us to introduce additional temporal and spatial dimension into youth transitions, recognising that certain stages involve taking risks, with unclear and unpredictable outcomes. The idea of speed that is inherent within a pinball game is also key in the 'social acceleration' context (Rosa 2013), in which these early career workers are embedded, allowing us to visualise elements of both space and time in complex, ongoing transition.

\section{Conclusions}

Mobility has become a salient feature of youth transitions and as such, the metaphors coined to explain them should also be reflective of this characteristic. Furlong stated that, 'Metaphors of transitions should be dynamic concepts which are capable of informing our knowledge of new or unfamiliar circumstances. That is their purpose.' $(2009,344)$. One application of Furlong's work is the attention to the role of structure in limiting (and enabling) the construction of life paths beyond the 'illusion of self-determination' (1997) that Furlong (together with Cartmel) posed as central in the way young people conceived of themselves. Structural factors remain key in the possibility of mobility for young people (Glick Schiller and Salazar 2013; Robertson, Harris, and Baldassar 2017). For Wyn:

There is an emerging consensus that this spatial concept of youth may need to be expanded, or that a different metaphor might be needed, to take full account of the young people's lives in the present and to acknowledge the qualities of relationships that enable young people to be productively connected to their worlds. (Wyn 2014, 99)

In this article, I suggest the idea of a 'pinball youth' as fertile grounds upon which to consider both structural factors and their interplay with agency. Furlong recognised that 'forms of consciousness may have changed, but people's locations within power structures still strongly impact on life changes' $(2009,344)$. The pinball metaphor embodies a mechanism of casualisation in mobile transitions which I see as salient in this interplay and that may also be apt to illustrate positions of peripherality. Similar to Batan (2015), who commenting on the public transportation metaphor argues that in the case of Istambay in the Philippines, the very access to any transportation may be out of reach, the pinball game urges us to consider that one's very participation in the game itself is not based on equal access: it is necessary to possess a coin to start the game. Once the game has started, there may be some space for individuals to enact reflexivity and agency.

In general, updating youth metaphors to incorporate mobility elements allows us, on one level, to strengthen the interdisciplinary nature of the field. On another level, it enables us to see aspects which an attentive reader of Furlong's work would appreciate, such as reflecting on how young people 'manage' themselves through engaging in mobility programmes; scrutinising how young people reshape their identities through 
encounters with new significant others and different cultures, whilst still bringing with them their background; capturing those elements of fluidity next to those of immobility and persistence of structural barriers as an ineliminable part of 'the mobility dream', incorporating global imaginaries in their life and career planning. Considering an element of mobility more directly is therefore a way to 'update' metaphors, as well as representing how 'mobile transitions' may fulfil what Robertson et al describe as the function of '[...] a broader research agenda that can build on critical interventions around youth, transitions and mobility from both youth studies and migration studies perspectives' $(2017,2)$.

\section{Notes}

1. This has, in turn, fuelled a rich debate on configurations of agency and structure in young people's lives, which would be impossible to summarise here. For an overview see Heinz (2009), Schoon and Lyons-Amos (2016), and to stay with Furlong's work, Evans and Furlong (1997) and Furlong (2009).

2. There is some scope to expand on the possible configurations of temporalities that may accompany an attention to spatiality, in particular in terms of fragmentation and diversion from the syncronicity to a linear path. I do, however, keep the focus on space in this contribution.

3. A critique of an overemphasis of this kind of literature on agency has been put forward (Tams and Arthur 2010; Cuzzocrea and Lyon 2011).

4. Italics are mine.

5. Some key authors of this strand are considered Sheller and Urry (2006), Urry (2007), Lefebvre (1974), Massey (2005), Thrift (2006) and Cresswell (2006).

6. By 'for us' and 'we' Ambrosini intends EU nationals outside of the UK, and maybe, to some extent, Italians in particular. The emphasis on 'for us' and 'we' is mine.

7. I wish to thank Hartmut Rosa for suggesting this metaphor in the first place, David Cairns for having long discussions on how it could be used to understand youth mobility, and Sebastiano Benasso for confronting on youth metaphors in general. Any criticism remains my full responsibility.

\section{Disclosure statement}

No potential conflict of interest was reported by the author.

\section{References}

Ackers, L. 2004. "Managing Relationships in Peripatetic Careers: Scientific Mobility in the European Union." Women's Studies International Forum 27 (3): 189-201.

Ambrosini, M. 2017. Migrazioni. Milano: Egea.

Arthur, M. 1994. "The Boundaryless Career: A New Perspective for Organizational Enquiry." Journal of Organizational Behaviour 15: 295-306.

Arthur, M. B., K. Inkson, and J. K. Pringle. 1999. The New Careers. London: Sage.

Arthur, M. B., and D. Rousseau. 1996a. The Boundaryless Career. Oxford: Oxford University Press.

Arthur, M. B., and D. Rousseau. 1996b. "A Career Lexicon for the 21st Century." The Academy of Management Executive (1993-2005) 10 (4): 28-39.

Batan, C. 2015. "The Istambays and Transition Crises. Locating Spaces of Social Sufferings and Hopes in the Philippines." In Youth and Inequality in Education: Global Actions in Youth Work, edited by M. Heathfield and D. Fusco, 112-134. London: Routledge.

Beck, U. 2000. The Brave New World of Work. Cambridge: Polity Press.

Benasso, S. 2013. Generazione shuffle. Traiettorie biografiche tra reversibilità e progetto. Roma: Aracne. 
Bennett, A. 1999. "Subcultures or Neo-Tribes? Rethinking the Relationship between Youth, Style and Musical Taste." Sociology 33 (3): 599-617.

Biggart, A., and A. Walther. 2006. "Coping with yo-yo-Transitions. Young Adults' Struggle for Support, between Family and State in Comparative Perspective." In A New Youth? Young People, Generations and Family Life, edited by C. Leccardi, and E. Ruspini, 41-62. Aldershot: Ashgate Publishing Limited.

Cairns, D. 2014. Youth Transitions, International Student Mobility and Spatial Reflexivity. Being Mobile? Basingstoke: Palgrave Macmillan.

Cairns, D. 2015. "Mapping the Youth Mobility Field. Youth Sociology and Student Mobility and Migration in a European Context." In Handbuch Kindheits- und Jugendsoziologie, edited by A. Lange, et al. (Hrsg.), 1-16. Wiesbaden: Springer.

Clarke, J., S. Hall, T. Jefferson, and B. S. Roberts. 2006 [1976]. "Subcultures, Cultures and Class." In Resistance Through Rituals, edited by S. Hall and T. Jefferson, 3-59. London: Routledge.

Cohen, L., and M. Mallon. 1999. "The Transition from Organisational Employment to Portfolio Working: Perceptions of 'Boundarylessness." Work, Employment \& Society 13 (2): 329-352.

Cresswell, T. 2006. On the Move: Mobility in the Modern Western World. London: Routledge.

Cresswell, T. 2010. "Towards a Politics of Mobility." Environment and Planning D: Society and Space 28: $17-31$.

Cuervo, H., and J. Wyn. 2014. "Reflections on the Use of Spatial and Relational Metaphors in Youth Studies." Journal of Youth Studies 17 (7): 901-915.

Cuzzocrea, V. 2018. "A Possibility to Square the Circle? Youth Uncertainty and the Imagination of Late Adulthood." Sociological Research Online 23 (3): 671-686.

Cuzzocrea, V. 2019. "Youth, Peripherality and the Mobility Discourse in Europe." In Social Justice in Times of Crisis and Hope: Young People, Wellbeing and the Politics of Education, edited by Shane Duggan, Kirsty Finn, Jessica Gagnon, Emily Gray, and Peter Kelly, 129-142. Leiden: Peter Lang.

Cuzzocrea, V., and D. Lyon. 2011. "Sociological Conceptualizations of 'Career': A Review and Reorientation." Sociology Compass 5 (12): 1029-1043.

Cuzzocrea, V., and G. Mandich. 2016. "Students Narratives of the Future: Imagined Mobilities as Forms of Youth Agency?" Journal of Youth Studies 19 (4): 552-567.

Ervas, F., and E. Gola. 2016. Che cos'è una metafora. Roma: Carocci.

Evans, K., and A. Furlong. 1997. "Metaphors of Youth Transitions: Niches, Pathways, Trajectories or Navigations." In Youth, Citizenship and Social Change in a European Context, edited by J. Bynner, L. Chisholm, and A. Furlong, 36-44. Aldershot: Ashgate.

Farrugia, D. 2016. "The Mobility Imperative for Rural Youth: The Structural, Symbolic and Non-representational Dimensions Rural Youth Mobilities." Journal of Youth Studies 19 (6): 836-851.

Farrugia, D., and B. E. Wood. 2017. "Youth and Spatiality: Towards Interdisciplinarity in Youth Studies." Young 25 (3): 209-218.

Fevre, R. 2007. "Employment Insecurity and Social Theory: The Power of Nightmares." Work, Employment \& Society 21: 517-535.

Finn, K., and M. Holton. 2019. Everyday Mobile Belonging. Theorising Higher Education Student Mobilities. London: Bloomsbury.

Forsyth, A., and A. Furlong. 2000. Socioeconomic Disadvantage and Access to Higher Education. Bristol: The Policy Press.

Forsyth, A., and A. Furlong. 2003. "Losing out? Socio-economic Disadvantage and Experience in Further and Higher Education. Bristol: The Policy Press.

Furlong, A. 2005. "Cultural Dimensions of Decisions about Educational Participation among 14- to 19Year-Olds: the Parts That Tomlinson doesn't Reach." Journal of Education Policy 20 (3): 379-389.

Furlong, A. 2006. "Not a Very NEET Solution: Representing Problematic Labour Market Transitions among Early School-Leavers." Work, Employment and Society 20 (3): 553-569.

Furlong, A. 2009. "Revisiting Transitional Metaphors: Reproducing Inequalities under the Conditions of Late Modernity." Journal of Education and Work 22 (5): 343-353.

Furlong, A. 2015. "Unemployment, Insecurity and Poor Wor: Young Adults in the New Economy." In Handbook of Children and Youth Studies, edited by J. Wyn and H. Cahill, 531-542. Singapore: Springer. 
Furlong, A., and F. Cartmel. 1997. Young People and Social Change: Individualization and Risk in Late Modernity. Maidenhead: Open University Press.

Furlong, A., and P. Kelly. 2005. "The Brazilianization of Youth Transitions in Australia." Social Issues 40 (2): $207-225$.

Glick Schiller, N., and N. B. Salazar. 2013. "Regimes of Mobility Across the Globe." Journal of Ethnic and Migration Studies 39 (2): 183-200.

Goodwin, J., and H. O'Connor. 2005. "Exploring Complex Transitions: Looking Back at the Transitions." Sociology 39: 201-221.

Grabowska, I. 2016. "The Transition from Education to Employment Abroad: The Experiences of Young People from Poland." Europe-Asia Studies 68 (8): 1421-1440.

Hall, D. T. 1976. Careers in Organizations. Goodyear: Santa Monica.

Hardy, A., A. Bennett, and B. Robards, eds. 2018. Neo-tribes. Consumption, Leisure and Tourism. Basingstoke: Palgrave MacMillan.

Heinz, W. R. 2009. "Structure and Agency in Transition Research." Journal of Education and Work 22 (5): $391-404$.

Heinz, W. R. 2003. "From Work Trajectories to Negotiated Careers. The Contingent Work Life Course." In Handbook of the Life Course, edited by Jeylan T Mortimer, and Michael J. Shanan, 185-204. New York: Kluwer Academic/Plenum Publishers.

Holdsworth, C. 2006. "'Don't you Think you're Missing Out, Living at Home?' Student Experiences and Residential Transitions." The Sociological Review 54 (3): 495-519.

Holdsworth, C. 2013. Family and Intimate Mobilities. Basingstoke: Palgrave MacMillan.

Inkson, K. 2004. "Images of Career: Nine Key Metaphors." Journal of Vocational Behaviour 65: 96-111. Inkson, K. 2007. Understanding Careers: Metaphors of Working Lives. London: Sage.

Jokinen, E., and S. Veijola. 1997. "The Disoriented Tourist: The Figuration of the Tourist in Contemporary Cultural Critique." In Touring Cultures: Transformations of Travel and Theory, edited by C. Rojeck and J. Urry, 23-51. London: Routledge.

Kohli, M. 1986. "The World we Forget: A Historical Review of the Life Course." In Later Life: The Social Psychology of Aging, edited by V. W. Marshall, 271-303. Beverly Hills, CA: SAGE.

Krzaklewska, E. 2019. "Youth, Mobility and Generations - the Meanings and Impact of Migration and Mobility Experiences on Transitions to Adulthood." Studia Migracyjne - Przeglad Polonijny 171 (1): 41-59.

Leccardi, C., V. Cuzzocrea, and B. G. Bello. 2018. "Youth as a Metaphor. An Interview with Carmen Leccardi." Journal of Modern Italian Studies 23 (1): 684-699.

Lefebvre, H. 1974. The Production of Space. Oxford: Blackwell.

MacDonald, R., T. Shildrick, C. Webster, and D. Simpson. 2005. "Growing up in Poor Neighbourhoods: The Significance of Class and Place in the Extended Transitions of 'Socially Excluded' Young Adults." Sociology 39 (5): 873-891.

Maffesoli, M. 1996. The Time of the Tribes. The Decline of Individualism in Mass Society. London: Sage. Magaraggia, S., and S. Benasso. 2019. "In Transition... Where to? Rethinking Life Stages and Intergenerational Relations of Italian Youth." Societies 9 (1): 1-15.

Massey, D. 2005. For Space. London: Sage.

Mignot, P. 2004. "Metaphor and 'Career'." Journal of Vocational Behaviour 64 (3): 455-469.

Murphy-Lejeune, E. 2002. Student Mobility and Narrative in Europe. The New Strangers. London: Routledge.

Nicholson, N., and M. West. 1989. "Transitions, Work Histories, and Careers." In Handbook of Career Theory, edited by M. Arthur, D. Hall, and B. Lawrence, 181-201. New York: Cambridge University Press.

Orthony, A. 1975. "Why Metaphors are Necessary and not Just Nice." Educational Theory 25 (1): 45-53. Plöger, J., and S. Kubiak. 2018. "Becoming 'the Internationals' - How Place Shapes the Sense of Belonging and Group Formation of High-Skilled Migrants." International Migration \& Integration I first: 1-15.

Rigney, D. 2001. The Metaphorical Society. An Invitation to Social Theory. Oxford: Rowman and Littlefield publishers. 
Robertson, S., A. Harris, and L. Baldassar. 2017. "Mobile Transitions: A Conceptual Framework for Researching a Generation on the Move." Journal of Youth Studies 21 (2): 203-217.

Rodrigues, R. A., and D. Guest. 2010. "Have Careers Become Boundaryless?" Human Relations 6 (8): 1157-1175.

Rodrigues, R., D. Guest, and A. Budjanovcanin. 2016. "Bounded or Boundaryless? An Empirical Investigation of Career Boundaries and Boundary Crossing." Work, Employment \& Society 30 (4): 669-686.

Rojeck, C., and J. Urry. 1997. Touring Cultures: Transformations of Travel and Theory. London: Routledge.

Rosa, H. 2013. Social Acceleration: A New Theory of Modernity. New York: Columbia University Press. Sackmann, R., and M. Wingens. 2003. "From Transitions to Trajectories: Sequence Types." In Social Dynamics of the Life Course. Transition, Institutions and Interrelations, edited by W. R. Heinz, and V. W. Marshall, 93-112. Hawthorne, NY: Aldine De Gruyter.

Salazar, N. B. 2010. "Towards an Anthropology of Cultural Mobilities." Crossings: Journal of Migration and Culture 1: 53-68.

Salazar, N. B. 2017. “Key Figures of Mobility: An Introduction." Social Anthropology 25 (1): 5-12.

Schoon, I., and M. Lyons-Amos. 2016. "Diverse Pathways in Becoming an Adult: The Role of Structure, Agency and Context." Research in Social Stratification and Mobility 46 (A): 11-20.

Sennett, R. 1998. The Corrosion of Character: The Personal Consequences of Work in the New Capitalism. London: Norton.

Sharma, J. R. 2013. "Marginal but Modern: Young Nepali Labour Migrants in India." Young 21 (4): 347362.

Sheller, M., and J. Urry. 2006. "The New Mobilities Paradigm." Environment and Planning A. 38 (2): 207226.

Sørensen, N. U., and M. Pless. 2017. "Living on the Periphery of Youth: Young People's Narratives of Youth Life in Rural Areas." Young 25 (4_suppl): 1S-17S.

Standing, G. 2011. The Precariat. The New Dangerous Class. London: Bloomsbury.

Tams, S., and M. B. Arthur. 2010. "New Directions for Boundaryless Career: Agency and Interdependence in a Changing World." Journal of Organizational Behavior 31: 629-646.

Tejerina, B. 2019. "Youth and Precariousness in Spain: Beyond a Waiting Time." In Youth and the Politics of the Present. Coping with Complexity and Ambivalence, edited by Enzo Colombo and Paola Rebughini, 88-100. London: Routledge.

Thomson, R., and R. Taylor. 2005. "Between Cosmopolitanism and the Locals: Mobility as a Resource in the Transition to Adulthood." Young 13 (4): 327-342.

Thrift, N. 2006. "Space." Theory, Culture and Society 23 (2-3): 139-146.

Tomaney, J. 2014. Progress in Human Geography 38 (1): 131-140.

Urry, J. 2007. Mobilities. Cambridge: Polity Press.

Waters, J. L. 2018. "In Anticipation: Educational (Im)mobilities, Structural Disadvantage, and Young People's Futures." Journal of Intercultural Studies 39 (6): 673-687.

White, R. J., and A. E. Green. 2015. "The Importance of Socio-spatial Influences in Shaping Young People's Employment Aspirations: Case Study Evidence from Three British Cities." Work, Employment and Society 29 (2): 295-313.

Williams, R. 1976. "Career." In Keywords. A Vocabulary of Culture and Society, edited by R. Williams, 5253. London: Fontana Press.

Willis, P. E. 2006 [1976]. "The Cultural Meaning of Drug use." In Resistance Through Rituals, edited by S. Hall and T. Jefferson, 88-99. London: HarperCollins.

Wyn, J. 2014. "Conceptualising Transitions to Adulthood." New Directions for Adult and Continuing Education 143: 5-16.

Wyn, J., S. Lantz, and A. Harris. 2011. "Beyond the 'Transitions' Metaphor: Family Relations and Young People in Late Modernity." Journal of Sociology 48 (1): 3-22. 